\title{
Impaired vagal heart rate control in coronary artery disease
}

\author{
K E JUHANI AIRAKSINEN, MARKKU J IKÄHEIMO, \\ MARKKU K LINNALUOTO, MATTI NIEMELÄ, JUHA T TAKKUNEN \\ From the Cardiovascular Division, Department of Medicine, Oulu University Central Hospital, Finland
}

SUMMARY Heart rate variation in deep breathing, a sensitive non-invasive measure of cardiac parasympathetic activity, was measured in 63 patients with coronary artery disease, in 22 patients with atypical chest pain, and in 20 healthy symptom free volunteers. There was significantly less heart rate variation in deep breathing in the patients with coronary artery disease than in the healthy subjects. Twenty patients $(32 \%)$ with coronary artery disease had lower than normal variation in heart rate. The patients with chest pain showed an intermediate heart rate response to deep breathing. Sinus arrhythmia in the patients with coronary artery disease was not related to the functional class, medication, number or location of narrowed vessels, or to the left ventricular ejection fraction, and end diastolic pressure.

These results suggest that impairment of the parasympathetic nervous function is common in coronary artery disease.

The harmful effects of increased sympathetic activity after myocardial infarction are well established and the beneficial effects of sympathetic blockade in reducing mortality in high-risk patients have been recognised. ${ }^{1-3}$ Recently, attention has also been directed toward the electrophysiological effects of the parasympathetic nervous system. Reduced vagal activity is associated with an increased frequency of cardiac death, ${ }^{4-6}$ and parasympathetic blockade may precipitate ventricular arrhythmias including ventricular fibrillation. ${ }^{78}$

The majority of patients with acute myocardial infarction show evidence of autonomic disturbances during the acute stage of the attack. ${ }^{910}$ The suggestion that there is dysfunction of the parasympathetic nervous system in stable coronary artery disease $^{112}$ and after myocardial infarction ${ }^{1314}$ is, however, more controversial and based on relatively small series of patients. We have evaluated parasympathetic nervous function in coronary artery disease by standard non-invasive cardiovascular tests and have related our findings to the clinical and angiographic features of coronary artery disease.

Requests for reprints to Dr K E Juhani Airaksinen, Cardiovascular Department, Department of Medicine, Oulu University Central Hospital, SF-90220 Oulu, Finland.

Accepted for publication 14 July 1987

\section{Patients and methods}

\section{PATIENTS}

We studied 63 patients ( 57 men, six women) with coronary artery disease. They were consecutive patients referred for elective cardiac catheterisation in our hospital and fulfilled the following inclusion criteria: age $<60$ years; no valvar heart disease, hypertension, manifest heart failure, or atrial fibrillation; not on antiarrhythmic medication or other medication known to have anticholinergic activity; and no diabetes mellitus or uraemia.

The mean age of the patients was 50 years (range 33-59) and 36 patients had had a myocardial infarction (eight anterior, 15 inferior, and 13 non-Q wave). None was in the acute stage of the attack. Seven patients were in New York Heart Association class IV, 36 patients in class III, and 20 patients in class II. Their medication included $\beta$ blockers in 42 cases $(67 \%)$, calcium antagonists in 29 cases $(46 \%)$, nitrates in 47 cases $(75 \%)$, digitalis in 11 cases $(18 \%)$, and diuretics in nine cases $(14 \%)$.

The control group of 20 healthy subjects ( 10 men, 10 women) of the same age group (mean age 46, range $36-55$ years) was recruited among the employees of a nearby pulp mill and among hospital staff. None was taking any medication known to affect autonomic nervous function. They were healthy as 
shown by history, physical examination, chest $x$ rays, echocardiogram, and exercise electrocardiogram.

A group of 22 patients (10 men, 12 women) with atypical chest pain was also assessed to evaluate the potential effects of long term antianginal medication and reduced physical activity on the autonomic control of heart rate. They were consecutive patients catheterised because of disabling symptoms and fulfilling the inclusion criteria. Their mean age was 47 years (range 35-59 years) and all had normal electrocardiograms, chest $x$ rays, echocardiograms, left ventricular cineangiograms, and coronary angiograms. Their medication included $\beta$ blockers and nitrates in 14 cases $(64 \%)$, calcium antagonists in 10 cases $(45 \%)$, diuretics in three cases $(13 \%)$, and digitalis in one case $(5 \%)$. Informed consent was obtained from all the subjects.

\section{CARDIAC CATHETERISATION}

All patients underwent left-sided cardiac catheterisation, including selective coronary arteriography performed by the Judkins' technique. Biplane left ventricular cineangiography was performed in the $45^{\circ}$ right anterior oblique position. The angiographic findings were interpreted by two independent observers who were unaware of the tests of the autonomic nervous function. A stenosis causing reduction of $>50 \%$ in the luminal diameter of a coronary artery was regarded as an important lesion. Left ventricular pressures were recorded with a Statham 235Ia transducer, and a data acquisition system (Hewlett-Packard 5400B) was used for analysis of pressure.

\section{TESTS OF AUTONOMIC NERVOUS FUNCTION}

The tests of autonomic nervous function were performed by specially trained nurses in the cardiovascular laboratory on patients in a postabsorptive state during the morning of the day before cardiac catheterisation. The patients were on their regular medication. Smoking and coffee drinking were not allowed in the morning before the tests. The heart rate was recorded with an instantaneous beat to beat rate recorder (Hewlett-Packard 8812 A rate computer). After a demonstration of the procedures and 10 minutes of supine rest the patients were asked to take six deep breaths. The depth of respiration is not critical as long as it is more than $40 \%$ of the vital capacity, but the rate of breathing is important and was standardised at six per minute. ${ }^{1516}$ The difference between the maximum and minimum heart rate during each breath was measured and the mean was taken as the heart rate variation during deep breathing (fig 1).

About 1-2 minutes after forced breathing the
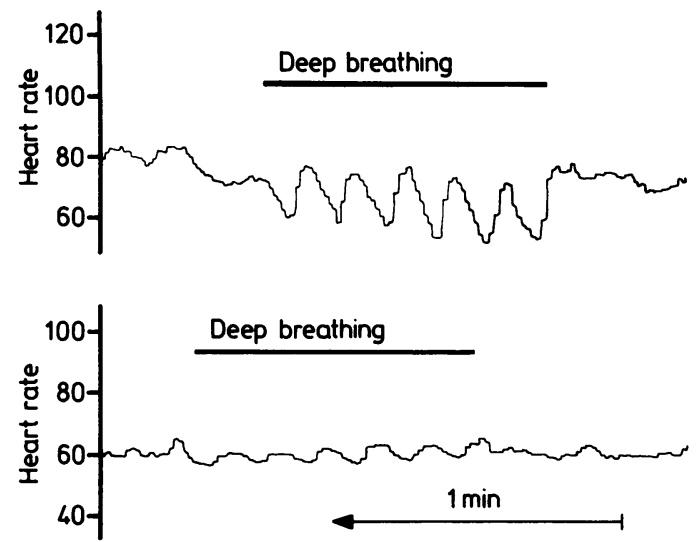

Fig 1 Normal heart rate variation during deep breathing in a healthy subject (above) and a blunted heart rate variation in a patient with coronary artery disease (below).

patients stood up quickly. The shortest RR interval at around the fifteenth beat after standing and the longest RR interval at around the thirtieth beat after standing were measured to show the response of the heart rate to standing (the $30: 15$ ratio). ${ }^{16}$ Generally accepted normal values were used to evaluate these tests. ${ }^{16}$

Supine heart rate was determined as the mean rate over a $30 \mathrm{~s}$ period before standing up. The mean heart rate of the last $30 \mathrm{~s}$ during the two minutes' standing was taken as the standing heart rate. Blood pressure was measured with a sphygmomanometer while the patient was lying down and after $30-60$ s of standing.

The reproducibility of the tests was assessed by examining 11 subjects (three with coronary artery disease) twice at an interval of at least two days. The mean (SD) difference in heart rate variation during deep breathing between test 1 and test 2 was 0 (4) (SD) beats/min (NS). The corresponding difference in the 30:15 ratio was $+0.05(0.19)$ (NS).

To assess ventricular parasympathetic reflexes, ${ }^{17}$ we measured the degree of bradycardia induced by coronary arteriography-that is the shortest $R R$ interval at the beginning of each coronary injection and the longest RR interval at around the end of each injection-and the induced maximum lengthening was expressed as a percentage. Only cases in which Urografin 76 was used as the contrast medium and who received no atropine as premedication were included in the analysis.

To assess the effects of cardiovascular medication on the tests of autonomic nervous function the drugs were gradually withdrawn at least two days (digitalis one week) before the tests in 12 patients with stable 
Table 1 Heart rate and blood pressure changes evoked by standing up and the catheterisation data in the study groups (mean (SD))

\begin{tabular}{|c|c|c|c|}
\hline Variable & $\begin{array}{l}C A D \text { patients } \\
(n=63)\end{array}$ & $\begin{array}{l}\text { Controls } \\
(n=20)\end{array}$ & $\begin{array}{l}\text { Patients with } \\
\text { chest pain }(n=22)\end{array}$ \\
\hline $\begin{array}{l}\text { Heart rate, supine (beats } / \mathrm{min} \text { ) } \\
\text { Heart rate, standing (beats } / \mathrm{min} \text { ) } \\
\text { The } 30: 15 \text { ratio }\end{array}$ & $\begin{array}{l}67(12) \\
82(14) \ddagger \\
1 \cdot 21(0 \cdot 15)\end{array}$ & $\begin{array}{l}69(11) \\
83(15) \\
1 \cdot 27(0 \cdot 21)\end{array}$ & $\begin{array}{l}73(11) \\
93(14) \\
1 \cdot 24(0 \cdot 13)\end{array}$ \\
\hline $\begin{array}{l}\text { Blood pressure, supine (mm Hg): } \\
\text { Systolic } \\
\text { Diastolic }\end{array}$ & $\begin{array}{r}130(18) \\
82(10)\end{array}$ & $\begin{array}{r}126(14) \\
82(11)\end{array}$ & $\begin{array}{r}128(15) \\
80(13)\end{array}$ \\
\hline $\begin{array}{l}\text { Blood pressure, standing }(\mathrm{mm} \mathrm{Hg}) \text { : } \\
\text { Systolic } \\
\text { Diastolic } \\
\text { LV end diastolic pressure }(\mathrm{mm} \mathrm{Hg}) \\
\text { LV end diastolic volume }(\mathrm{ml})^{\star} \\
\text { LV ejection fraction }(\%)^{\star} \\
\text { RR interval change in response to coronary arteriography }(\%) \dagger\end{array}$ & $\begin{array}{l}122(17) \\
85(11) \\
12 \cdot 9(5 \cdot 0) \\
160(34) \S \\
59(10) \S \\
66(67)\end{array}$ & $\begin{array}{l}121(18) \\
80(14) \\
- \\
-\end{array}$ & $\begin{array}{l}118(17) \\
85(12) \\
14 \cdot 7(6 \cdot 0) \\
126(28) \\
70(7) \\
50(42)\end{array}$ \\
\hline
\end{tabular}

CAD, coronary artery disease; LV, left ventricular. ${ }^{\star}$ Data on 35 patients with CAD and 12 patients with chest pain. + Data on 35 patients with CAD and nine with chest pain. Difference $v s$ patients with chest pain: $\ddagger \mathrm{p}<0.05, \S p<0.01$.

coronary artery disease and the tests were repeated one day after the treatment was resumed ( $\beta$ blockers in nine patients, nitrates in nine patients, calcium antagonists in seven patients, and digitalis in four patients).

STATISTICAL ANALYSIS

Differences between the three groups were evaluated by analysis of variance followed by the Bonferroni modification of $t$ test. A paired or unpaired $t$ test was used when appropriate and Fisher's test was used to evaluate the differences in frequencies. Standard formulas were used to calculate the linear correlations.

\section{Results}

CATHETERISATION DATA

Table 1 shows the catheterisation data in the patients. Five $(8 \%)$ of the patients with coronary artery disease had an important stenosis of left main coronary artery; 34 patients $(54 \%)$ had three vessel disease, $11(17 \%)$ two vessel disease, and $13(20 \%)$ one vessel disease.

\section{PARASYMPATHETIC NERVOUS FUNCTION}

There was less variation in heart rate during deep breathing in patients with coronary artery disease than in healthy subjects (difference between means $5,95 \%$ confidence interval one to 10 beats $/ \mathrm{min}$ ), but not in patients with chest pain (fig 2). In the subgroup analysis of the patients, $40 \%$ of those with local akinesia or dyskinesia, $26 \%$ of the remaining patients with coronary artery disease, and $18 \%$ of the patients with chest pain had abnormal $(\leqslant 10$ beats/min) heart rate variation in deep breathing. One healthy subject also had a heart rate variation just below the lower limit of normal (fig 2).
The number or location of affected vessels did not significantly affect the variation in heart rate during deep breathing. Nor was the variation related to New York Heart Association class, left ventricular ejection fraction, or end diastolic pressure in the patients with coronary artery disease. The medication taken by patients with abnormal heart rate vari-

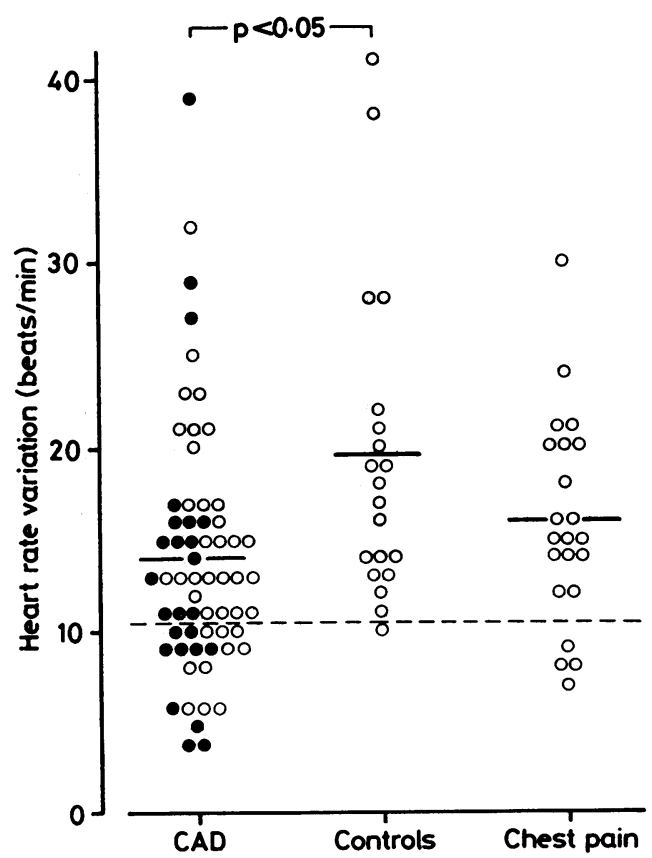

Fig 2 Heart rate variation in deep breathing in patients with coronary disease (CAD), healthy subjects, and patients with chest pain. Patients with transmural myocardial infarction ( ). Broken line shows lower limit of normal. 
Table 2 Clinical and catheterisation data on patients with coronary artery disease who had normal or abnormal heart rate variation during deep breathing (mean (SD))

\begin{tabular}{|c|c|c|}
\hline Variable & $\begin{array}{l}\text { Normal heart rate } \\
\text { variation }(n=43)\end{array}$ & $\begin{array}{l}\text { Abnormal heart rate } \\
\text { variation }(n=20)\end{array}$ \\
\hline $\begin{array}{l}\text { Age } \\
\text { Mean NYHA class }\end{array}$ & $\begin{array}{c}50(6) \\
2 \cdot 8\end{array}$ & $\begin{array}{c}51(5) \\
2.9\end{array}$ \\
\hline \multicolumn{3}{|l|}{ Treatment: } \\
\hline$\beta$ Blockers & $29(67 \%)$ & $13(65 \%)$ \\
\hline Calcium antagonists & $23(53 \%)$ & $6(30 \%)$ \\
\hline Nitrates & $30(70 \%)$ & $17(85 \%)$ \\
\hline Digitalis & $9(21 \%)$ & $2(10 \%)$ \\
\hline Diuretics & $8(19 \%)$ & $1(5 \%)$ \\
\hline Heart rate, supine (beats/min) & $67(10)$ & $66(16)$ \\
\hline Heart rate, standing (beats/min) & $83(12)$ & $79(17)$ \\
\hline The $30: 15$ ratio & $1 \cdot 23(0 \cdot 16)$ & $1 \cdot 15(0 \cdot 11)^{\star}$ \\
\hline \multicolumn{3}{|l|}{ Blood pressure, supine (mm Hg): } \\
\hline Systolic & $131(20)$ & $126(13)$ \\
\hline Diastolic & $82(10)$ & $81(10)$ \\
\hline \multicolumn{3}{|l|}{ Blood pressure, standing ( $\mathrm{mm} \mathrm{Hg}$ ): } \\
\hline Systolic & $126(17)$ & $115(17)^{\star}$ \\
\hline \multirow{2}{*}{\multicolumn{3}{|c|}{ Location of coronary stenosis: }} \\
\hline & & \\
\hline Left main coronary artery & $4(9 \%)$ & $1(5 \%)$ \\
\hline Left anterior descending branch & $38(88 \%)$ & $19(95 \%)$ \\
\hline Circumflex branch & $32(74 \%)$ & $13(65 \%)$ \\
\hline Right coronary artery & $32(74 \%)$ & $13(65 \%)$ \\
\hline LV end diastolic pressure (mm Hg) & $12 \cdot 8(5 \cdot 9)$ & $13 \cdot 3(5 \cdot 3)$ \\
\hline LV end diastolic volume ( $\mathrm{ml})$ & $158(37)$ & $166(26)$ \\
\hline LV ejection fraction $(\%)$ & $60(10)$ & $57(11)$ \\
\hline $\mathbf{R} \mathbf{R}$ interval change in response to coronary arteriography (\%) & $71(72)$ & $53(48)$ \\
\hline
\end{tabular}

NYHA, New York Heart Association; LV, left ventricular. Difference between the groups: ${ }^{\star} p<0.05$.

ation did not differ significantly from that of the patients with normal heart rate variation (table 2 ) or of the patients with chest pain. Heart rate variation in deep breathing was not significantly related to age in the patients with coronary artery disease $(r=$ $-0.05)$, but tended to diminish with age in the other subjects $(r=-0 \cdot 29, n=42)$.

Changes in heart rate evoked by standing up (the 30:15 ratio) as well as supine and standing blood pressure were not significantly different in the three groups (table 1). In the subgroup analysis of patients with coronary artery disease, the standing systolic blood pressure and the 30:15 ratio of the patients with abnormal heart rate variation were, however, lower than those in the patients with normal heart rate variation $(p<0.05)$ (table 2$)$.

The mean (SD) heart rate variation in deep breathing was similar after withdrawal and reinstitution of the cardiovascular medication $(13.8(7 \cdot 4)$ and $11 \cdot 6(7 \cdot 1)$ beats $/ \mathrm{min}$, respectively, NS) in the 12 patients in which it is evaluated.

The bradycardia caused by coronary arteriography was not significantly different in patients with coronary artery disease and those with chest pain.

\section{Discussion}

The variation in heart rate induced by deep breathing is the single most sensitive and reproducible non-invasive test of cardiac parasympathetic activity. ${ }^{1819}$ It correlates closely with invasive measurement of parasympathetic heart rate control-for example, baroreflex sensitivity. ${ }^{18}$ Several physiological mechanisms contribute to respiratory sinus arrhythmia. These include both reflex mechanisms (pulmonary stretch receptors, baroreceptors, Bainbridge reflex) and the direct interaction of the respiratory and cardiovascular medullary centres. ${ }^{20}$ The fact that vagotomy and atropine abolish respiratory sinus arrhythmia and that recorded vagal efferent activity closely predicts the magnitude of heart rate variation shows that parasympathetic efferents are mainly responsible for mediating these effects. $^{2021}$ Changes in heart rate induced by standing up also reflect mainly parasympathetic heart rate control, but are not so useful because they are less sensitive and have a wider range of normal responses, especially in older people. ${ }^{22} 23$

Our study suggests that cardiac vagal efferent activity is depressed in coronary artery disease. Earlier studies of autonomic nervous function in coronary artery disease have given somewhat divergent results. Ryan et al found impaired parasympathetic response to facial immersion, but normal sympathetic pressor responses in 27 patients three months after myocardial infarction. ${ }^{13}$ On the other hand, Bennett et al found impaired sympathetic responses in a group of 18 asymptomatic patients studied at least one year after myocardial 
infarction. ${ }^{14}$ The difference in parasympathetic responses did not reach statistical significance, although the values were comparable to those in the present study. The heart rate response to the Valsalva manoeuvre has been reported to be abnormally low in patients with coronary artery disease, ${ }^{11}$ although they may have an exaggerated heart rate response to carotid sinus massage. ${ }^{12}$ The apparent discrepancies may result from the fact that various tests reflect different aspects of autonomic nervous function.

We cannot explain the impairment of vagal control of heart rate in coronary artery disease. Heart rate variation tends to decline with age in healthy subjects, ${ }^{23}{ }^{24}$ but heart rate variation in deep breathing was not affected by age in patients with coronary artery disease, so it seems that minor differences in age between the groups were not a crucial factor. Earlier observations suggest that medication was unlikely to have had any major impact on our findings. ${ }^{61425}$ This view is supported by the findings that the withdrawal of medication did not significantly alter the heart rate variation and that patients with abnormal and normal heart rate variation in deep breathing were on similar medication.

The level of physical activity may affect the parasympathetic tone and reflex heart rate control. ${ }^{26}$ Interestingly, the patients with chest pain also had slightly diminished heart rate responses to deep breathing, which might suggest that reduced physical activity caused by disabling symptoms may contribute to the blunting of heart rate variation. The severity of symptoms did not, however, correlate with the heart rate variation in deep breathing.

Earlier experimental studies have shown that transmural infarction can interrupt both the afferent and efferent limbs of the autonomic innervation of the myocardium apical to the infarction. ${ }^{27}$ Heart rate variation in deep breathing or the degree of bradycardia caused by coronary arteriography, however, were not significantly reduced in patients with transmural myocardial infarction compared with other patients with coronary artery disease. Nor was heart rate variation in deep breathing related to the location or number of diseased vessels or to left ventricular function. So it seems that reduced vagal efferent activity in coronary artery disease cannot be predicted by any specific feature of the disease.

The role of the parasympathetic nervous system in protecting the heart against serious ventricular arrhythmias and sudden death has recently attracted attention. The interaction of the parasympathetic nervous system with the sympathetic nervous system can buffer the deleterious effect of sympathetic storm on the threshold for ventricular fibrillation. ${ }^{28} 29$ Experimental studies have shown that dogs with a healed myocardial infarction and $\leftarrow$. reduced levels of cardiac vagal activity are liable to $\overrightarrow{\vec{m}}$ exercise-induced ventricular fibrillation and that subsequent increases in vagal activity protect against ventricular fibrillation. ${ }^{26}$ In accordance with this, $\frac{\overline{\bar{n}}}{\text {. }}$ reduced respiration-related variation in heart rate is $\vec{D}$ associated with an increased frequency of cardiac $c_{0}$ death both in middle aged men $^{5}$ and after myo- $-\infty$ cardial infarction. ${ }^{630}$ These studies suggest that $a 0$ diminished heart rate variation in deep breathing, $a_{-}^{-}$ simple bedside measure of cardiac vagal activity might identify a subpopulation of patients with coronary artery disease who are at an increased risk of sudden death. It is not yet known whether inter-o ventions known to augment the vagal activity-fors example pharmacological ones, ${ }^{31}$ and exercise pro- $N$ grammes, or on the other hand blocking of sym-o pathetic activity, might be of particular value in this group of patients.

This study was supported by Paavo Nurmi Founda tion for Cardiovascular Research.

\section{References}

1 Han J, Garcia de Jalon P, Moe GK. Adrenergic effectso on ventricular vulnerability. Circ Res 1964;14: 516-24.

2 Wilhelmsson C, Vedin JA, Wilhelmsen L, Tibblin G, Werkö L. Reduction of sudden deaths after吕 myocardial infarction by treatment with alprenolol. Lancet 1974;ii:1157-60.

3 The Norwegian multicenter Study Group. Timolol- 3 induced reduction in mortality and reinfarction in patients surviving acute myocardial infarction. $N$. Engl J Med 1981;304:801-7.

4 Billman GE, Schwartz PJ, Stone HL. Baroreceptor reflex control of heart rate: a predictor of sudden cardiac death. Circulation 1982;66:874-80.

5 Hinkle LE, Carver ST, Plakun A. Slow heart rates and increased risk of cardiac death in middle-aged men. Arch Intern Med 1972;129:732-48.

6 Kleiger RE, Miller JP, Bigger JT Jr, Moss AJ.O Decreased heart rate variability and its association with increased mortality after acute myocardia infarction. Am J Cardiol 1987;59:256-62.

7 Massumi RA, Mason DT, Amsterdam EA, et al. Ventricular fibrillation and tachycardia after intravenous atropine for treatment of bradycardias. N Engl J Med N $_{\text {1972;287:336-8. }}$
.

8 Schwartz PJ, Billman GE, Stone HL. Autonomig mechanisms in ventricular fibrillation induced by myocardial ischemia during exercise in dogs with healed myocardial infarction. Circulation? 1984;69:790-800.

9 Kirby BJ. Circulatory reflexes in myocardial infarction Br Heart J 1977;39:168-72.

10 Imaizumi $T$, Takeshita A, Makino N, Ashihara $T \frac{\mathscr{\rho}}{\mathrm{Q}}$ Yamamoto K, Nakamura M. Impaired baroreflex 
control of vascular resistance and heart rate in acute myocardial infarction. Br Heart $J$ 1984;52:418-21.

11 Tristani FE, Kamper DG, McDermott DJ, Peters BJ, Smith JJ. Alterations of postural and . Valsalva responses in coronary heart disease. Am J Physiol 1977;233:H694-9.

12 Brown KA, Maloney JD, Smith H, Hartzler GO, Ilstrup DM. Carotid sinus reflex in patients undergoing coronary angiography: relationship of degree and location of coronary artery disease to response to carotid sinus massage. Circulation 1980;62:697-703.

13 Ryan C, Hollenberg M, Harvey DB, Gwynn R. Impaired parasympathetic responses in patients after myocardial infarction. Am J Cardiol 1976;37:1013-8.

14 Bennett T, Wilcox RG, Hampton JR. Cardiovascular reflexes in patients after myocardial infarction. Effect of long-term treatment with beta-adrenoreceptor antagonists. Br Heart J 1980;44:265-70.

15 Bennett T, Farquhar IK, Hosking DJ, Hampton JR. Assessment of methods for estimating autonomic nervous control of the heart in patients with diabetes mellitus. Diabetes 1978;27:1167-74.

16 Ewing DJ, Clarke BF. Diagnosis and management of diabetic autonomic neuropathy. $\mathrm{Br} M e d \mathrm{~J}$ 1982;285:916-8.

17 Carson RP, Lazzara R. Hemodynamic responses initiated by coronary stretch receptors with special reference to coronary arteriography. Am J Cardiol 1970;25:571-8.

18 Watkins PJ, Mackay JD. Cardiac denervation in diabetic neuropathy. Ann Intern Med 1980;92:304-7.

19 Ewing DJ, Borsey DQ, Bellavere F, Clarke BF. Cardiac autonomic neuropathy in diabetes: comparison of measures of R-R interval variation. Diabetologia 1981;21:18-24.

20 Katona PG, Jih F. Respiratory sinus arrhythmia: noninvasive measure of parasympathetic cardiac control. J Appl Physiol 1975;39:801-5.

21 Katona PG, Poitras JW, Barnett GO, Terry BS. Car- diac vagal efferent activity and heart period in the carotid sinus reflex. Am J Physiol 1970;218:1030-7.

22 Dyrberg T, Benn J, Christiansen JS, Hilsted J, Nerup J. Prevalence of diabetic autonomic neuropathy measured by simple bedside tests. Diabetologia 1981;20:190-4.

23 Pfeifer MA, Weinberg CR, Cook D, Best JD, Reenan A, Halter JB. Differential changes of autonomic nervous system function with age in man. Am J Med 1983;75:249-58.

24 O'Brien IAD, O'Hare P, Corrall RJM. Heart rate variability in healthy subjects: effect of age and the derivation of normal ranges for tests of autonomic function. Br Heart J 1986;55:348-54.

25 Pfeifer MA, Cook D, Brodsky J, et al. Quantitative evaluation of cardiac parasympathetic activity in normal and diabetic man. Diabetes 1982;31:339-45.

26 Billman GE, Schwartz PJ, Stone HL. The effects of daily exercise on susceptibility to sudden cardiac death. Circulation 1984;69:1182-9.

27. Barber MJ, Mueller TM, Davies BG; Gill RM, Zipes DP. Interruption of sympathetic and vagalmediated afferent responses by transmural myocardial infarction. Circulation 1985;72:623-31.

28 Muscholl E. Peripheral muscarinic control of norepinephrine release in the cardiovascular system. Am J Physiol 1980;239:H713-20.

29 Hohnloser SH, Verrier RL, Lown B. Effects of adrenergic and muscarinic receptor stimulation on serum potassium concentrations and myocardial electrical stability. Cardiovasc Res 1986;20:891-6.

30 Wolf MM, Varigos GA, Hunt D, Sloman JG. Sinus arrhythmia in acute myocardial infarction. Med $J$ Aust 1978;ii:52-3.

31 Dibner-Dunlap ME, Eckberg DL, Magid NM, Cintron-Trevino NM. The long-term increase of baseline and reflexly augmented levels of human vagal-cardiac nervous activity induced by scopolamine. Circulation 1985;71:797-804. 